\title{
Comments
}

\section{Another view of the role of FMRP in translational regulation}

\author{
F. Zalfa and C. Bagni * \\ Dipartimento di Biologia, Università di Roma "Tor Vergata", Via della Ricerca Scientifica 1, 00133 Rome (Italy) \\ Fax: +39062023500, e-mail: claudia.bagni@uniroma2.it \\ Istituto di Farmacologia, Fondazione Santa Lucia, IRCCS, Via Ardeatina, 306 Rome (Italy)
}

In a recent review Denman et al. [1] discuss how FMRP regulates translation and the recognition of the target mRNAs. Their view is incomplete and needs, we think, some comment. There are, in general, four possible ways for FMRP to recognise its target mRNAs.

The first mechanism proposed by Denman and collaborators [2] is the direct binding of FMRP to oligo(U) elements on the mRNA. Chen et al. [3], however, identified a series of putative FMRP targets using a cDNA-SELEX, of which only $20 \%$ contain the U-rich region. This finding implies the existence of other mechanisms of target mRNA recognition by FMRP.

The second described mechanism concerns the binding of FMRP to a secondary structure called the 'G-quartet' $[4,5]$. Here, the authors' main comment $[1]$ is that the archetypical G-quartet mRNA, MAP1B, may not be a target for translational regulation because the initial finding by Brown et al. [6] was not MAP1B. However, there are independent demonstrations that MAP1B mRNA translational efficiency changes between FMRP wild-type and FMRP knockout (KO) mouse brain [7], while Drosophila MAP1B (Futsch) has been found to be translationally regulated in mutants for the homologous FMR1 gene (dFXR) [8]. Moreover, Feng and colleagues [9] have recently demonstrated that MAP1B mRNA translation and microtubule stability are controlled by FMRP during neuronal development.

The third possible mechanism of target recognition by FMRP is via micro RNAs (miRNAs). Both the human FMRP and its Drosophila orthologue have been found associated with miRNAs, probably regulating mRNA translation $[10,11]$. Although the means by which this regula-

\footnotetext{
* Corresponding author.
}

tion occurs is not clear, this mechanism was not discussed by the authors [1].

As a fourth possible mechanism, FMRP can recognise its target mRNAs indirectly by binding to the non-coding RNA BC1 which in turn anneals to the target mRNAs [7] Denman et al. [1] dispute this model on three principal grounds: the strength and the specificity of the FMRP$\mathrm{BC} 1$ interaction, the significance of complementarities between BC1 RNA and the targeted mRNAs and the distribution of FMRP on polysome gradients. Regarding the first point, the authors state that the FMRP-BC1 RNA association is weak and could be interpreted as marginal. The conclusion is almost the opposite: the reaction occurred at $750 \mathrm{mM} \mathrm{NaCl}$, a concentration which dissociates weak RNA-protein complexes; meaning that the interaction is quite strong. Furthermore, in the two studies cited by Denman to discredit the FMRP-BC1 interaction $[12,13]$, no experiment on FMRP-BC1 binding is shown, thus making it difficult to understand on what basis this statement is made.

In addition, the authors state that eIF4A and PABP bind so strongly to $\mathrm{BC} 1$ that even if FMRP is bound to $\mathrm{BC} 1$ RNA, it would 'rapidly be displaced by these proteins' [1]. However, displacement can only occur if the proteins compete for the same binding site. eIF4A is an RNA helicase which has no known RNA-binding selectivity, and PABP associates with the oligo(A) stretch of $\mathrm{BC} 1$. Therefore, competition can only occur if FMRP binds to the same oligo(A) stretch with comparable affinity. To our knowledge, no such experiments have been published. Regarding the inverse homology between $\mathrm{BC} 1 \mathrm{RNA}$ and the targeted mRNAs, the homology for MAP1B spans a region of $21 \mathrm{nt}$, out of which $19 \mathrm{nt}$ can form strong base-pairing with $\mathrm{BC} 1 \mathrm{RNA}$. This is as strong as a 
miRNA/mRNA interaction but even much weaker interactions occur in vivo: RNA-RNA recognition can occur with only 5-7 bases pairing, the small nuclear RNAs involved in the splicing reaction being a typical example [14]. Moreover, the FMRP-BC1-mRNA interaction was also demonstrated by inhibiting the recognition $\mathrm{BC} 1$ RNA-mRNA target using a chemically synthesized oligo [7]. As a final proof of this annealing and recognition, using naked biotinylated $\mathrm{BC} 1$, the same mRNAs that were found to be translationally dysregulated were fished out in vitro [7]. This clearly demonstrates that $\mathrm{BC} 1$ has the potential to anneal to the targeted mRNAs.

Finally, with respect to the distribution of FMRP on a polysome gradient, we deem it important to underline that the percentage of FMRP that is found to co-associate with polysomes and with mRNP of the gradient varies according to the mechanical conditions of homogenisation, buffer composition, tissue and duration of the procedure [7, 15-17]. In vitro data also showed that FMRP could regulate protein synthesis inhibiting $80 \mathrm{~S}$ formation [18], and in Drosophila, dFXR seems to be mainly associated with mRNPs [10], so black-and-white thinking is clearly not appropriate for these kinds of biochemical preparations. The still unsolved question concerns the function of FMRP on mRNPs and on polysomes.

In summary, as far as FMRP-mRNA interactions are concerned, it is quite clear from the papers published hitherto that not all FMRP target mRNAs have recognisable homology to the $5^{\prime}$ end of BC1 RNA. Neither, however, do all FMRP target mRNAs have the G-quartet or an oligo (U) stretch. Clearly, there are different ways for FMRP to recognise its target mRNAs. FMRP has been shown to be a multifaceted protein, and its lack causes a heterogeneous phenotype. One can easily envision, therefore, that FMRP interacts in different contexts with different mRNAs. Moreover, the mechanisms described above could co-operate to obtain stable binding to an mRNA that contains several different, but weakly conserved elements. Of interest in this respect is to note that binding activity to oligo(U) RNA, to the G-quartet, to $\mathrm{BC} 1$ or to the miRNAs may be ascribed to different RNA-binding domains on the FMRP protein and could therefore occur simultaneously. In fact, the RGG box has been shown to be involved in the G-quartet recognition, but there are still the two $\mathrm{KH}$ domains and the $\mathrm{N}$ terminus, another unmentioned RNA-binding domain [19, 20], that are still orphans for targets.

1 Denman R. B., Dolzhanskaya N. and Sung Y. J. (2004) Regulating a translational reulator: mechanisms cells use to control the activity of the fragile $\mathrm{X}$ mental retardation protein. Cell. Mol. Life Sci. 61: 1714-1728

2 Dolzhanskaya N., Sung Y. J., Conti J., Currie J. R. and Denman R. B. (2003) The fragile X mental retardation protein interacts with U-rich RNAs in a yeast three-hybrid system. Biochem. Biophys. Res. Commun. 305: 434-441
3 Chen L., Yun S. W., Seto J., Liu W. and Toth M. (2003) The fragile $\mathrm{X}$ mental retardation protein binds and regulates a novel class of mRNAs containing $U$ rich target sequences. Neuroscience 120: 1005-1017.

4 Schaeffer C., Bardoni B., Mandel J. L., Ehresmann B., Ehresmann C. and Moine H. (2001) The fragile X mental retardation protein binds specifically to its mRNA via a purine quartet motif. EMBO J. 20: 4803-4813

5 Darnell J. C., Jensen K. B., Jin P., Brown V., Warren S. T. and Darnell R. B. (2001) Fragile X mental retardation protein targets $\mathrm{G}$ quartet mRNAs important for neuronal function. Cell 107: 489-499

6 Brown V., Jin P., Ceman S., Darnell J. C., O’Donnell W. T., Tenenbaum S. A. et al. (2001) Microarray identification of FMRP-associated brain mRNAs and altered mRNA translational profiles in fragile $X$ syndrome. Cell 16: 477-487

7 Zalfa F., Giorgi M., Primerano B., Moro A., Di Penta A., Reis S. et al. (2003) The fragile $X$ syndrome protein FMRP associates with $\mathrm{BC} 1 \mathrm{RNA}$ and regulates the translation of specific mRNAs at synapses. Cell 112: 317-327

8 Zhang Y. Q., Bailey A. M., Matthies H. J., Renden R. B., Smith M. A., Speese S. D. et al. (2001) Drosophila fragile X-related gene regulates the MAP1B homolog Futsch to control synaptic structure and function. Cell 107: 591-603

9 Lu R., Wang H., Liang Z., Ku L., O’Donnell W. T., Li W. et al. (2004) The fragile X protein controls microtubule-associated protein $1 \mathrm{~B}$ translation and microtubule stability in brain neuron development. Proc. Natl. Acad. Sci. USA 101: 15201-15206

10 Ishizuka A., Siomi M. C. and Siomi H. (2002) A Drosophila fragile X protein interacts with components of RNAi and ribosomal proteins. Genes Dev. 16: 2497-2508

11 Jin P., Zarnescu D. C., Ceman S., Nakamoto M., Mowrey J. et al. (2004) Biochemical and genetic interaction between the fragile X mental retardation protein and the microRNA pathway. Nat. Neurosci. 7: 113-117

12 Sung Y.-J. and Denman R. B. (2001) RNA binding properties of the fragile $\mathrm{X}$ syndrome mental retardation protein FMRP. Recent Res. Dev. Biophys. Biochem. 1: 109-123

13 Denman R. B. (2003) Déjà vu all over again: FMRP binds Urich target mRNAs. Biochem. Biophys. Res. Commun. 310: 1-7

14 Dandekar T. (2002) RNA Motifs and Regulatory Elements, 2nd edn. Springer, Berlin

15 Siomi M. C., Zhang Y., Siomi H. and Dreyfuss G. (1996) Specific sequences in the fragile $\mathrm{X}$ syndrome protein FMR1 and the FXR proteins mediate their binding to $60 \mathrm{~S}$ ribosomal subunits and the interactions among them. Mol. Cell. Biol. 16: 3825-3832

16 Stefani G., Fraser C. E., Darnell J. C. and Darnell R. B. (2004) Fragile $\mathrm{X}$ mental retardation protein is associated with translating polyribosomes in neuronal cells. J. Neurosci. 18: 9272 9276

17 Khandjian E. W., Huot M., Tremblay S., Davidovic L., Mazroui R. and Bardoni B. (2004) Biochemical evidence for the association of fragile $\mathrm{X}$ mental retardation protein with brain polyribosomal ribonucleoparticles. Proc. Natl. Acad. Sci. USA 101: 13357-13362

18 Laggerbauer B., Ostareck D., Keidel E., Lederer A. O. and Fischer U. (2001) Evidence that fragile X mental retardation protein is a negative regulator of translation. Hum. Mol. Genet. 10: $329-338$.

19 Adinolfi S., Bagni C., Musco G., Gibson T., Mazzarella L. and Pastore A. (1999) Dissecting FMR1, the protein responsible for fragile $\mathrm{X}$ syndrome, in its structural and functional domains. RNA 9: 1248-1258

20 Adinolfi S., Ramos A., Martin S. R., Dal Piaz F., Pucci P., Bardoni B. et al. (2003) The N-terminus of the fragile X mental retardation protein contains a novel domain involved in dimerization and RNA-binding. Biochemistry 42: 10437-10444 